\title{
A Hypothesis Concerning the Effect of Schedule on the Pattern of 5-Fluorouracil Toxicity
}

\author{
Arthur J. Weiss \\ Division of Medical Oncology, Thomas Jefferson School of Medicine, Philadelphia, PA, USA \\ Email: ajw.law150@gmail.com \\ Received 29 January 2015; accepted 11 March 2015; published 12 March 2015 \\ Copyright (C 2015 by author and Scientific Research Publishing Inc. \\ This work is licensed under the Creative Commons Attribution International License (CC BY). \\ http://creativecommons.org/licenses/by/4.0/ \\ c) (i) Open Access
}

\begin{abstract}
The significant effect that scheduling has upon the severity and types of drug toxicity has been known for many years. Evidence is available demonstrating that the schedule chosen will substantially effect the relative distribution of drug to various target organs. It has been shown that a likely cause for this with doxorubicin is that the efficiency of the various enzyme complexes responsible for disposing of the drug can be affected by scheduling. We believe a similar process can explain the marked effect that scheduling has on the pattern of 5 -fluorouracil toxicity and present both clinical and computer data to illustrate this.
\end{abstract}

\section{Keywords}

Effect of Scheduling upon Selective Organ 5-Fluorouracil Toxicity, Computer Modeling

\section{Introduction}

Up to the present time most initial anti-cancer chemotherapeutic regimes have been empirically designed, with several different types of schedule being compared. It is not unusual for a different pattern of organ toxicities to change as the structure of the protocol changes. It is the premise of this paper that these differences arise, at least in part, because the relative efficiency of enzymatic processes related to the intake and disposition of the drug by the tumor and various normal organs systems are dependent upon the schedule used. If the pharmacologic parameters of the tumor and various sensitive normal tissues are known, a computer program can help in formulating an optimum schedule. This paper, using 5-fluorouracil as an example, attempts to illustrate this.

\section{Methods}

The protocols used as the basis for the bolus schedule were that of Curreri et al. [1], Weiss et al. [2], and Ken- 
nedy et al. [3]. They consisted of a loading dose, given over 3 to 4 days by daily bolus, followed by weekly drug given by bolus.

That used as basis for the low dose continuous infusion schedule was described by Lemon et al. [4] [5]. The total amount required varied among patients and daily dosage selected, but on average, an increase of $155 \%$ of the bolus dose was required to obtain comparable hematologic toxicity.

\section{Clinical Results}

The clinical results of the bolus groups can be summarized as follows.

\section{Bolus [1]-[3]}

Hematologic Toxicity grade 3, Stomatitis grade 3, Diarrhea, grade 4 Cardiac grade 0 . Initial Mortality 30\% Adjusted dose Mortality 1.2\%.

\section{Continuous Infusion [4] [5]}

Hematologic Toxicity grade 3, Stomatitis grade 3.5, Diarrhea, grade 0.5. Cardiac grade 1, Mortality $0.5 \%$. Total Dose required for equivalent hematologic toxicity $=$ Average Bolus Dose $\times 1.55$.

\section{Computer Data [6]}

The basis of the computer program is described in reference [6]. The Components chosen for the computer simulation are noted in Table 1 and results of the computer calculations concerning the relative organ uptakes as they are affected by schedule change are presented in Table 2.

\section{Table 1. Michaelis-Menten Equation $|\mathrm{dS} / \mathrm{dT}=\mathrm{S} * \mathrm{Vmax} /(\mathrm{Km}+\mathrm{S})| \mathrm{S}=$ 5-fluorouracil.}

\begin{tabular}{ccccc}
\hline & Vmax in & Km in & Vmax out & Km out \\
\hline WBC & 6 & 2 & 2 & 2.5 \\
GUT & 8 & 3 & 1 & 2 \\
ORAL & 5 & 3.5 & 3 & 1.5 \\
MUCOSA & 4 & 3 & 4 & 2 \\
HEART & & & & 1.5 \\
\hline
\end{tabular}

Table 2. Amount of 5-fluorouracil retained by each organ system.

\begin{tabular}{|c|c|c|c|}
\hline & BY BOLUS & BY 21 DAY & By 6 DAY \\
\hline Total Dose required & & Infusion & Infusion \\
\hline \multicolumn{4}{|l|}{ So that retained dose in } \\
\hline \multicolumn{4}{|l|}{ Hematopoietic Tissue $=$} \\
\hline $100 \mathrm{U}$ & $143 \mathrm{U}$ & $250 \mathrm{U}$ & $183 \mathrm{U}$ \\
\hline Retained BY Hematopoietic & $100 \mathrm{U}$ & $100 \mathrm{U}$ & $100 \mathrm{U}$ \\
\hline \multicolumn{4}{|l|}{ Tissue $\{\mathrm{DLT}\}$} \\
\hline \multirow[t]{3}{*}{ Retained by GUT } & $236 \mathrm{U}$ & $82 \mathrm{U}$ & $106 \mathrm{U}$ \\
\hline & When 143 total & When 250 total & When 183 total \\
\hline & Units given & Units given & Units given \\
\hline Retained by ORAL & $104 \mathrm{U}$ & $132 \mathrm{U}$ & $125 \mathrm{U}$ \\
\hline \multirow[t]{2}{*}{ MUCOSA } & When 143 total & When 250 total & When 183 total \\
\hline & Units given & Units given & Units given \\
\hline \multirow[t]{3}{*}{ Retained By HEART } & $79 \mathrm{U}$ & $139 \mathrm{U}$ & $94 \mathrm{U}$ \\
\hline & When 143 Total & When 250 total & When 183 total \\
\hline & Units Given & Units given & Units given \\
\hline
\end{tabular}


Representative values of Vmax's and Km's were obtained from references [7]-[10].

These findings of drug retention for each organ system parallel all the clinical findings concerning drug toxicity described in the methods section as well as the general medical literature [1]-[5] [11]-[14].

\section{Discussion}

The administration of almost all anti-cancer chemotherapeutic agents commonly affects one or more potentially fatal, dose limiting organ systems, with the hematopoietic component being by far the most common. Fortunately this is almost always rapidly and essentially completely reversible, as is toxicity to the oral mucosa and mucosa of the intestine. Other forms of toxicity such as that to the heart, kidney, or nervous system may be partially or totally irreversible [15] [16]. While hematological toxicity is dose limiting in the majority of agents in common use, the degree of toxicity to other organ systems can also be dose limiting and be substantially affected by the schedule used. The degree of toxicity to the heart associated with the administration of one of the anthracyclines [17] [18], the degree of toxicity to the gut from the administration of 5-fluorouracil [1]-[5] [11][14], and the degree of neurotoxicity from the taxanes [19] are significantly decreased when the drug is given by slow intravenous infusion while the degree of stomatitis from these agents is increased by repeated low dose injections or by continuous, slow infusion.

In some cases, such as with doxorubicin, the total dose required to in hematological toxicity is relatively independent of schedule [17] [18], in others, 5-fluorouracil for example, it is dependent upon the schedule used [11] [14].

5-fluorouracil is a pyrimidine derivative whose primary mode of action is believed to be inhibition of thymidylate synthetase thereby preventing DNA synthesis. However, its effect on cell metabolism is known to be complex, interfering with RNA function and protein synthesis are also believed to be factors in its anti-tumor activity [20]-[23]. Both uptake and disposition of the drug are known to be active processes with dihydropyrimidine dehydrogenase being a major factor, especially in the liver; several other enzyme complexes are also known to be important and present in different strengths in many tissues [24]-[28]. This is unlike doxorubicin cellular metabolism, in which passive diffusion, an essentially linear process, is believed to be responsible for most cellular ingress processes, and many cells lack any means of disposing of intra-cellular drug [18] [29]-[31]. Thus compared to programs studying the effect of schedule changes upon doxorubicin toxicity, the programs analyzing cellular metabolism of 5-fluorouracil are complex.

Surveying the many studies involving 5-Fluorouracil reveal the following. With almost all the original protocols and many that follow, the drug was given by bolus, usually over a period of 15 minutes or less, daily for 3 to 4 days, commonly followed by weekly bolus injections. In the early trials drug induced mortality was quite high, primarily due to a gram negative septicemia secondary to overwhelming diarrhea and drug induced necrosis of bowel mucosa. In essentially all of the protocols where the 5-fluorouracil was given by bolus, WBC suppression, stomatitis and diarrhea were major factors [3]-[6]. Somewhat later, protocols were devised in which the drug was given by infusion, either for relatively short period of times or over many days. Here the pattern of toxicity differs. While the stomatitis was similar or somewhat what increased, the amount of diarrhea was either markedly diminished or totally gone. Despite equivalent degrees of neutropenia, drug induced mortality was also markedly lowered. The amount of drug required to induce an equivalent degree of neutropenia was also substantially increased [3] [4]. Unlike the anthracyclines, evidence has been presented that 5-fluorouracil was more cardio-toxic when given by slow, low dose infusion than when it was given by bolus [12]-[14] [32]-[37].

The computer program used predicted that, assuming the various VMax and Km values entered were representative of true values, the amount of the drug required to produce a specific degree of hematological toxicity was significantly affected by the type of schedule, primarily because both efficiency of uptake and disposition of the drug are dependent upon his schedule. The computer also predicted a marked decrease in the retention of drug by the gut when the drug is given by low dose continuous infusion, thus explaining the clinical finding of the marked decrease in diarrhea and sepsis found when the drug is given by slow infusion. It also predicts an increase in the amount of drug accumulated by the heart and mucosa of the mouth and upper airway. Therefore, variations in enzymatic functions concerning drug uptake and disposal of various target organs can explain the clinical findings concerning the effect of schedule modification on selective drug toxicity.

The relationship of the pharmacologic parameters of both tumor and normal tissues and scheduling has rarely been discussed, even though the effect of a change of schedule upon differential organ toxicity can be major and 
associated with a substantial shift in drug away from a critical target tissue such as the heart [3]-[9] [15] [16]. Thus Pacciarini et al. demonstrated that dividing a weekly dose of doxorubicin into 4 parts decreased the doxorubicin AUC in the heart of 3LL tumor bearing mice from 17,121 U to $5919 \mathrm{U}$, a loss of approximately 65\%, while uptake in tumor increased a minimal amount and uptake in spleen showed a minimal decrease [38]. Both this paper and a previous paper that utilized a computer program demonstrated that these findings could be predicted to occur, provided that the appropriate parameters were used [3] [19]. With protocols in which drug enters cells of all tissues including tumor by passive diffusion and there exists one or more organ systems that have active enzymatic systems that can neutralize the drug, protocols that keep the plasma drug as low as possible will protect that organ system. Also this protocol would not protect those tissues that lack such a protective system. With drugs such as 5-fluorouracil where active enzymatic processes control both drug influx and disposition, and are known to exist in almost all cell types, including hematopoietic tissue, cardiac myocytes, and cells of the gastrointestinal tract, the situation is much more complex, since unlike the situation with doxorubicin, where qualitative differences exist between various cell types, here the influx and efflux processes may not differ between cell types the only differences are quantitative [34]-[37]. Nevertheless, as demonstrated in Table 2, these differences can result in marked changes in the differential uptake and disposition of 5-fluorouracil between various target tissue types.

An important but unknown factor in this approach is that the effect of schedule change upon tumor uptake has not been addressed. One reason for this is that tumor response rate in those tumors that are sensitive to 5-fluorouracil appear to be relatively independent of choice of schedule [3]-[15] [18]. The marked changes is the degree of toxicity with changes in scheduling suggest that similar changes in tumor drug sensitivity can occur with schedule changes; perhaps determining the appropriate constants for each tumor will substantially increase the effectiveness of such therapy.

The fact that such major changes in the pattern of toxicity occurs when schedule is altered suggest that further schedule modification may yield a pattern of toxicity that is more acceptable as far as non hematological toxicity is concerned. This is illustrated in Table 2 where a modification of scheduling modifies all aspects of non hematological toxicity to a more acceptable level for the two forms of toxicity that are life threatening, while causing only slight changes in other areas of toxicity.

It is not our contention that the pharmacologic parameters chosen are the real factors; It is only that this example illustrates that specific parameters of complexes responsible for uptake into both the neoplasm and specific normal tissues that limit the amount of drug a patient may receive may differ enough to markedly influence the pattern of toxicity caused by any specific agent, thus altering the LCT. This may occur even though the enzymes concerned are identical; only their specific environment, i.e. $\mathrm{pH}$, electrolyte composition, etc varies, thus changing the efficiency of the enzyme complexes involved in both 5-fluorouracil and doxorubicin metabolism [23] [24].

It also illustrates the principle that theoretically, provided that the data is available, a computer program may optimize the pattern of non hematological drug toxicity other than a hypothetical effect of drug upon regional blood flow [17], the author is not familiar with any other proposal to explain the marked effect that changes in scheduling has upon the pattern of drug toxicity.

\section{Conclusion}

A hypothesis has been put forward to explain the marked effect that modification of scheduling has upon the differential organ toxicities of many anti-cancer agents. The hypothesis states that local factors and the concentration of drug influence the relative activity of the enzymatic processes responsible for drug influx and disposition and the marked difference in drug concentration resulting from a change from short term bolus therapy to low dose continuous infusion can have a substantial effect upon the relative activities of these enzymatic processes in the target organs primarily due to the relative inefficiency of enzymatic activity at high tissue drug levels.

\section{References}

[1] Curreri, A.R., Ansfield, F.J., McIver, F.A., Waisman, H.A. and Heidelberger, C (1958) Clinical Studies with 5-Fluorouracil. Cancer Research, 18, 478-484.

[2] Weiss, A.J. and Jackson, L.G. (1961) The Effect of 5-Fluorouracil Upon Carcinomas of Gastrointestinal Tract and Related Organs. American Journal of Gastroenterology, 35, 138-146. 
[3] Kennedy, B.J. and Theologides, A. (1961) The Role of 5-Fluorouracil in Malignant Disease. Annals of Internal Medicine, 55, 719-722. http://dx.doi.org/10.7326/0003-4819-55-5-719

[4] Lemon, H.M. (1960) Reduction of 5-Fluorouracil Toxicity in Man with Retention of Anticancer Effects by Prolonged Intravenous Administration in 5 Percent Dextrose. Cancer Chemotherapy Reports, 8, 97-101.

[5] Lemon, H.M., Modzen, P.J., Mirchandni, R., Farmer, D.A. and Athans, J. (1963) Decreased Intoxication by Fluorouracil When Slowly Administered in Glucose. JAMA, 185, 1012-1016.

[6] Valko, P. and Vajda, S. (1989) Advanced Scientific Computing in Basic With Applications in Chemistry. Biology and Pharmacology. Elsevier, Amsterdam, 268.

[7] Gupta, N., Saleem, A., Kötz, B., Osman, S., Aboagye, E.O., Phillips, R., Vernon, C., Wasan, H., Jones, T., Hoskin, P.J. and Price, P.M. (2006) Carbogen and Nicotinamide Increase Blood Flow and 5-Fluorouracil Delivery but Not 5-Fluorouracil Retention in Colorectal Cancer Metastases. Clinical Cancer Research, 12, 3115-3123. http://dx.doi.org/10.1158/1078-0432.CCR-05-0513

[8] Ojugo, A.S., McSheehy, P.M., Stubbs, M., Alder, G., Bashford, C.L., Maxwell, R.J., Leach, M.O., Judson, I.R. and Griffiths, J.R. (1998) Influence of $\mathrm{pH}$ on the Uptake of 5-Fluorouracil into Isolated Tumour Cells. British Journal of Cancer, 77, 873-879. http://dx.doi.org/10.1038/bjc.1998.144

[9] Milano, G. and Chamorey, A.L. (2002) Clinical Pharmacokinetics of 5-Fluorouracil with Consideration of Chronopharmacokinetics. Chronobiology International, 19, 177-189. http://dx.doi.org/10.1081/CBI-120002597

[10] Coustère, C., Mentré, F., Sommadossi, J.P., Diasio, R.B. and Steimer, J.L. (1991) A Mathematical Model of the Kinetics of 5-Fluorouracil and Its Metabolites in Cancer Patients. Cancer Chemotherapy and Pharmacology, 28, 123-129. http://dx.doi.org/10.1007/BF00689701

[11] Fraile, R.J., Baker, L.H., Buroker, T.R., Horwitz, J. and Vaitkevicius, V.K. (1980) Pharmacokinetics of 5-fluorouracil Administered Orally, by Rapid Intravenous and by Slow Infusion. Cancer Research, 40, 2223-2228.

[12] Ploylearmsaeng, S.A., Fuhr, U. and Jetter, A. (2006) How May Anticancer Chemotherapy with Fluorouracil Be Individualized? Clinical Pharmacokinetics, 45, 567-592. http://dx.doi.org/10.2165/00003088-200645060-00002

[13] van Kuilenburg, A.B. and Maring, J.G. (2013) Evaluation of 5-Fluorouracil Pharmacokinetic Models and Therapeutic Drug Monitoring in Cancer Patients. Pharmacogenomics, 14, 799-811. http://dx.doi.org/10.2217/pgs.13.54

[14] Gamelin, E.C., Delva, R., Jacob, J., Merrouche, Y., Raoul, J.L., Pezet, D., Dorval, E., Piot, G., Morel, A. and Boisdron-Celle, M. (2008) Individual Fluorouracil Dose Adjustment Based on Pharmacokinetic Follow-Up Compared with Conventional Dosage: Results of a Multicenter Randomized Trial of Patients with Metastatic Colorectal Cancer. Journal of Clinical Oncology, 26, 2099-2105. http://dx.doi.org/10.1200/JCO.2007.13.3934

[15] Davey, P. and Tudhope, G.R. (1983) Anticancer Chemotherapy. British Medical Journal (Clin Res Ed), 287, 110-113. http://dx.doi.org/10.1136/bmj.287.6385.110

[16] DeVita, Hellman, and Rosenberg's Cancer: Principles and Practice of Oncology (Cancer: Principles \& Practice (DeVita). 9th Edition, 2011, Lippincott Williams and Wilkins, Philadelphia.

[17] Berrak, S.G., Ewer, M.S., Jaffe, N., Pearson, P., Ried, H., Zietz, H.A. and Benjamin, R.S. (2001) Doxorubicin Cardiotoxicity in Children: Reduced Incidence of Cardiac Dysfunction Associated with Continuous-Infusion Schedules. Oncology Reports, 8, 611-614.

[18] Weiss, A.J., Stoloff, I.L., Simoes, A.C. and Lackman, R.D. (2014) The Relation between the Initial Type of Schedule Used to Administer Doxorubicin and Long Term Doxorubicin Cardiotoxicity. Journal of Cancer Therapy, 5, 11451152.

[19] Ramalingam, S., Perry, M.C., La Rocca, R.V., Rinaldi, D., Gable, P.S., Tester, W.J. and Belani, C.P. (2008) Comparison of Outcomes for Elderly Patients Treated with Weekly Paclitaxel in Combination with Carboplatin versus the Standard 3-Weekly Paclitaxel and Carboplatin for Advanced Nonsmall Cell Lung Cancer. Cancer, 113, 542-546. http://dx.doi.org/10.1002/cncr.23583

[20] Maehara, Y., Nagayama, S., Okazaki, H., Nakamura, H., Shirasaka, T. and Fujii, S. (1981) Metabolism of 5-Fluorouracil in Various Human Normal and Tumor Tissues. Gan, 72, 824-827.

[21] Tanaka-Nozaki, M., Onda, M., Tanaka, N. and Kato, S. (2001) Variations in 5-Fluorouracil Concentrations of Colorectal Tissues as Compared with Dihydropyrimidine Dehydrogenase (DPD) Enzyme Activities and DPD Messenger RNA Levels. Clinical Cancer Research, 7, 2783-2787.

[22] Presant, C.A., Wolf, W., Waluch, V., Wiseman, C., Kennedy, P., Blayney, D., Brechner, R.R., et al. (1994) Association of Intratumoral Pharmacokinetics of Fluorouracil with Clinical Response. Lancet, 343, 1184-1187. http://dx.doi.org/10.1016/S0140-6736(94)92399-X

[23] Takiguchi, N., Saito, N., Nunomura, M., Kouda, K., Oda, K., Furuyama, N. and Nakajima, N. (2001) Use of 5-FU Plus Hyperbaric Oxygen for Treating Malignant Tumors: Evaluation of Antitumor Effect and Measurement of 5-FU in In- 
dividual Organs. Cancer Chemotherapy and Pharmacology, 47, 11-14. http://dx.doi.org/10.1007/s002800000190

[24] Sasako, M., Terashima, M., Ichikawa, W., Ochiai, A., Kitada, K., Kurahashi, I., Sakuramoto, S., Katai, H., Sano, T. and Imamura, H. (2014) Impact of the Expression of Thymidylate Synthase and Dihydropyrimidine Dehydrogenase Genes on Survival in Stage II/III Gastric Cancer. Gastric Cancer, Epub ahead of print.

[25] Pratt, S., Shepard, R.L., Kandasamy, R.A., Johnston, P.A., Perry III, W. and Dantzig, A.H. (2005) The Multidrug Resistance Protein 5 (ABCC5) Confers Resistance to 5-Fluorouracil and Transports Its Monophosphorylated Metabolites. Molecular Cancer Therapeutics, 4, 855-863.

[26] Guo, Y., Kotova, E., Chen, Z., Lee, K., Hopper-Borge, E., Belinsky, M.G. and Kruh, G.D. (2003) MRP8, ATP-Binding Cassette C11 (ABCC11), Is a Cyclic Nucleotide Efflux Pump and a Resistance Factor for Fluoropyrimidines 2',3'-dideoxycytidine and 9'-(2'-phosphonylmethoxyethyl)adenine. Journal of Biological Chemistry, 278, 2950929514.

[27] Kruh, G., Zeng, H., Rea, P., Liu, G.S., Chen, Z.S., Lee, K. and Belinsky, M.G. (2001) MRP Subfamily Transporters and Resistance to Anticancer Agents. Journal of Bioenergetics and Biomembranes, 33, 493-501. http://dx.doi.org/10.1023/A:1012827221844

[28] Adachi, M., Reid, G. and Schuetz, J. (2002) Therapeutic and Biological Importance of Getting Nucleotides Out of Cells: A Case for the ABC Transporters, MRP4 and 5. Advanced Drug Delivery Reviews, 54, 1333-1342. http://dx.doi.org/10.1016/S0169-409X(02)00166-7

[29] Weiss, A.J., Barrueco, C.J., Kocsis, J.J. and Bianchi, C. (1984) Doxorubicin Efflux from Isolated Rat Hearts at 37\% and 25\% C. Federation of American Societies for Experimental Biology (Pharmacology).

[30] Loveless, H., Arena, E., Felsted, R.L. and Bachur, N.R. (1978) Comparative Mammalian Metabolism of Adriamycin and Daunorubicin. Cancer Research, 38, 593-598.

[31] Hartmann, G., Vassileva, V. and Piquette-Miller, M. (2005) Impact of Endotoxin-Induced Changes in P-Glycoprotein Expression on Disposition of Doxorubicin in Mice. Drug Metabolism and Disposition, 33, 820-828.

[32] Fontanella, C., Aita, M., Cinausero, M., Aprile, G., Baldin, M.G., Dusi, V., Lestuzzi, C., Fasola, G. and Puglisi, F. (2014) Capecitabine-Induced Cardiotoxicity: More Evidence or Clinical Approaches to Protect the Patients' Heart? OncoTargets and Therapy, 7, 1783-1791.

[33] Polk, A., Vistisen, K., Vaage-Nilsen, M. and Nielsen, D. (2014) A Systematic Review of the Pathophysiology of 5-Fluorouracil-Induced Cardiotoxicity. BMC Pharmacology and Toxicology, 15, 47. http://dx.doi.org/10.1186/2050-6511-15-47

[34] Saif, M.W., Garcon, M.C., Rodriguez, G. and Rodriguez, T. (2013) 5-Fluorouracil as an Alternative in Patients with Cardiotoxicity Associated with Infusion 5-Fluorouracil and Capecitabine: A Case Series. In Vivo, 27, 531-534.

[35] Kosmas, C., Kallistratos, M.S., Kopterides, P., Syrios, J., Skopelitis, H., Mylonakis, N., Karabelis, A. and Tsavaris, N. (2008) Cardiotoxicity of Fluoropyrimidines in Different Schedules of Administration: A Prospective Study. Journal of Cancer Research and Clinical Oncology, 134, 75-82.

[36] Tsavaris, N., Kosmas, C., Vadiaka, M., Efremidis, M., Zinelis, A., Beldecos, D., Sakelariou, D., Koufos, C. and Stamatelos, G. (2002) Cardiotoxicity Following Different Doses and Schedules of 5-Fluorouracil Administration for Malignancy-A Survey of 427 Patients. Medical Science Monitor, 8, PI51-P157.

[37] Lamberti, M., Porto, S., Zappavigna, S., Addeo, E., Marra, M., Miraglia, N., Sannolo, N., Vanacore, D., Stiuso, P. and Caraglia, M. (2014) A Mechanistic Study on the Cardiotoxicity of 5-Fluorouracil in Vitro and Clinical and Occupational Perspectives. Toxicology Letters, 227, 151-156. http://dx.doi.org/10.1016/j.toxlet.2014.03.018

[38] Pacciarini, M.A., Barbieri, B., Colombo, T., Broggini, M., Garattini, S. and Donelli, M.G. (1978) Distribution and Antitumor Activity of Adriamycin Given in a High Dose and a Repeated Low-Dose Schedule to Mice. Cancer Treatment Reports, 62, 791-800. 